\title{
Informing Primary School Nutritional Policy: Effects of Mid-Morning Snacks on Appetite and Energy Control
}

\author{
Penny L. S. Rumbold, Caroline J. Dodd-Reynolds, Emma J. Stevenson
}

Department of Sport, Exercise and Rehabilitation, Faculty of Health and Life Sciences, Northumbria University, Newcastle, UK. Email: penny.rumbold@northumbria.ac.uk

Received March $7^{\text {th }}, 2013$; revised April $7^{\text {th }}, 2013$; accepted April 14 ${ }^{\text {th }}, 2013$

Copyright (C) 2013 Penny L. S. Rumbold et al. This is an open access article distributed under the Creative Commons Attribution License, which permits unrestricted use, distribution, and reproduction in any medium, provided the original work is properly cited.

\begin{abstract}
The purpose of this research was to inform primary school nutritional policy by identifying which mid-morning snack would be more beneficial to consume from an appetite control perspective. During morning break 14 girls and 11 boys were provided with $160 \mathrm{ml}$ of semi-skimmed milk or $153 \mathrm{~g}$ of apple in a randomised crossover manner. Visual analogue scales were used to record hunger, prospective food consumption and fullness, immediately before and after breakfast, immediately before and after the mid-morning snack, and every $60 \mathrm{~min}$ until 21:00 on each day. School dinner/packed lunch energy intakes were assessed 90 min following the mid-morning snacks, in addition to evening energy intake. Children felt less hungry and could eat less when apple was consumed, however lunch and evening energy intakes were not different. Fluctuations in appetite did not translate into differences in energy intake therefore both milk and fruit should be promoted as mid-morning snacks in primary schools.
\end{abstract}

Keywords: Primary School Policy; Mid-Morning Snacks; Milk; Fruit; Appetite; Energy Intake

\section{Introduction}

Poor dietary practices of children have been identified as one factor contributing to the increased risk of overweight and obesity [1]. Recent data from the Avon Longitudinal Study of Parents and Children suggest that the incidence of obesity is the highest during mid-childhood (age 7 - $11 \mathrm{y}, 6.7 \%$ ), compared to early childhood (3 - 7 y, 5.1\%) and adolescence (11 - $15 \mathrm{y}, 1.6 \%)$ [2]. Consequently, it is suggested that obesity prevention schemes should focus on children within the mid-childhood age range $(7-11$ y) [2]. It has also been postulated that school settings represent imperative channels for influencing behaviour change from childhood through to adulthood [3].

At present UK primary schools have the choice of promoting one of two dietary intervention schemes, namely milk or fruit and vegetables. In 1971 and 1980 the provision of free school milk was withdrawn from all children over the age of $7 \mathrm{y}$ and children aged $5-7 \mathrm{y}$, respectively. Nowadays, some primary schools still choose to finance this scheme for children under the age of $7 y$, however local education authorities are not obliged to financially support this. More recently a national gov- ernment campaign known as "The School Fruit and Vegetable Scheme" [4] provides a free piece of fruit or vegetable each school day to all children aged $4-6$ y in infant, primary and special local authority maintained schools, whilst some schools also encourage the uptake of this scheme by their Key Stage 2 pupils $(7-11$ y). Therefore, typically during a school day, children consume either milk or fruit as mid-morning snacks. In light of the current and prospective levels of childhood obesity in the UK [5], it is important to establish the influence such mid-morning snacks may have on appetite and energy intake control in young children. Recent data in adolescent girls have shown a favourable relationship between milk consumption and BMI and body fat percentage [6], however at the time of writing, no data from an appetite control perspective is available. Such information would enable local education authorities to make evidence based decisions regarding the most beneficial dietary intervention scheme to promote in primary schools within the UK.

Acute food pre-load studies, exploring energy intake compensation in response to various food items, other than fruit and milk, have been conducted in children [7-13] and adolescents $[14,15]$, of which the findings are 
equivocal. There are some available studies which have specifically explored the influence of milk consumption on appetite control in young people, however these studies intervened chronically [16-19]. Moreover, when examining the paediatric food pre-load studies to date, there is a distinct lack of focus on the mid-childhood age range (7 - $11 \mathrm{y}$ ), in addition to the dietary interventions not being representative of the foods/drinks typically provided in schools. Furthermore, to the authors' knowledge only one of the studies [13] attempted to replicate a free-living school environment, whereby typical timings of a school day were considered in order to maintain ecological validity [20].

Therefore, in order to successfully inform primary school nutritional policy, the purpose of this study was to investigate the effect of milk or fruit consumption as mid-morning snacks, on subsequent appetite and energy intake in $7-10$ y primary school children.

\section{Materials and Methods}

\subsection{Study Design}

A within-subjects, randomised crossover design was used to compare energy intake, hunger, prospective food consumption and fullness, following the consumption of milk or fruit as mid-morning snacks. Two 1-d test sessions took place in a primary school setting, separated by 14-d.

The study was approved by the University of Northumbria, Faculty of Health and Life Sciences Ethics Committee. Written informed consent was obtained from both the children and parents/guardians prior to data collection.

\subsection{Participants and Recruitment}

All 7 - 10 y boys and girls $(n=\sim 200)$ from a local primary school in the North East of England were invited to take part. Participants were excluded if they had been diagnosed with any significant medical condition that may interfere with the testing, had aversions to the midmorning snacks or were off school due to illness. In addition, following completion of the study, data was withdrawn from the statistical analysis if the food and/or visual analogue scale (VAS) diaries were not sufficiently completed. Consequently, of the 98 children who commenced the study, 25 children's data was analysed (girls $\mathrm{n}=14$; boys $\mathrm{n}=11$ ).

During a preliminary testing session at the school, the children's stature and seated height were measured to the nearest $0.01 \mathrm{~m}$ using a Harpeden Portable Stadiometer (Holtain Limited, Pembs, UK) and body mass to the nearest $0.1 \mathrm{~kg}$ using Avery Balance scales (Avery Berkel Ltd., West Midlands, UK). These measures were used to calculate BMI $\left(\mathrm{kg} / \mathrm{m}^{2}\right)[21]$ and maturity offset [22], with the latter providing an indication of years from peak height velocity and thus maturation. In the presence of the research team, the children completed the Dutch Eating Behaviour Questionnaire for children (DEBQ-C) [23], to provide an indication of restrained eating prevalence within the sample. The children were also familiarised with the VAS diaries [24] and were asked to state their three favourite fruits. Participant characteristics are outlined in Table 1.

\subsection{Procedures}

For each year group $(3-5)$ the 1-d test sessions took

Table 1. Participant characteristics.

\begin{tabular}{|c|c|c|c|c|c|c|}
\hline & \multicolumn{2}{|c|}{ Girls $(n=14)$} & \multicolumn{2}{|c|}{ Boys $(\mathrm{n}=11)$} & \multicolumn{2}{|c|}{ All $(n=25)$} \\
\hline & Mean & $\mathrm{SE}$ & Mean & $\mathrm{SE}$ & Mean & $\mathrm{SE}$ \\
\hline Age (y) & 9.2 & 0.2 & 9.1 & 0.2 & 9.2 & 0.2 \\
\hline Body weight $(\mathrm{kg})^{1}$ & 30.6 & 2.4 & 28.9 & 1.9 & 29.8 & 1.6 \\
\hline Height $(\mathrm{cm})$ & 137.3 & 2.2 & 133.6 & 2.5 & 135.5 & 1.7 \\
\hline BMI $\left(\mathrm{kg} / \mathrm{m}^{2}\right)^{1}$ & 16.4 & 0.8 & 16.3 & 0.6 & 16.3 & 0.5 \\
\hline Number classified as under-weight $t^{2}$ & 2 & - & 0 & - & 2 & - \\
\hline Number classified as normal-weight $t^{2}$ & 11 & - & 11 & - & 22 & - \\
\hline Number classified as overweight/obese ${ }^{2}$ & 1 & - & 0 & - & 1 & - \\
\hline Maturity offset $(y)^{3}$ & -2.6 & 0.3 & -4.0 & $0.2^{*}$ & -3.1 & 0.2 \\
\hline DEBQ-C restrained eating score ${ }^{4}$ & 2.1 & 0.1 & 1.8 & 0.1 & 1.9 & 0.1 \\
\hline Number caucasian (\%) & 12 & - & 10 & - & 22 & - \\
\hline Number asian (\%) & 2 & - & 1 & - & 3 & - \\
\hline
\end{tabular}

${ }^{1}$ Three participant values missing (two girls and one boy); ${ }^{2}$ Classified according to current paediatric international reference curves; ${ }^{3}$ Maturity offset values missing for 11 participants (five girls and six boys), as regression equation not valid for children under the age of 8 y; ${ }^{4} \mathrm{DEBQ}-\mathrm{C}$, Dutch Eating Behavior Questionnaire for children; ${ }^{*}$ Maturity offset significantly different between genders $(P=0.02)$. 
place on the same week day (Monday = year 3; Thursday $=$ year 5; Friday = year 4), as these days did not involve physical education or any other active curriculum lessons. There was a period of 14-d between test sessions as the lunch menus at the school were dictated by a 3-wk rota imposed by the local education authority. The organisation of the two 1-d test sessions followed the typical timings of a school day to ensure the study was representative of the children's normal routine.

Prior to the first test session the children were asked (through liaising with the parents/guardians) to consume their usual breakfast at the time that they would usually consume this meal before school. The parents/guardians of the children were asked to record this information in a food diary. Weighed food diaries have been successfully used by parents to record the food intake of their children (4 - $10 \mathrm{y}$ ), and have been shown to be comparable to doubly labelled water (in a pilot study of the most recent UK National Diet and Nutrition Survey [25]). Prior to the second test session, the parents/guardians of the children were provided with a photocopy of the food and drink items and times that their children consumed breakfast prior to the first test session. This enabled replication of food and drink items, timings of consumption and portion sizes prior to the second test session [26].

Apple was the chosen fruit as this was in the three of the most popular rated fruits identified by the children during the preliminary testing session. Favourably for the purpose of this study, apples have a similar low glycaemic index value to that of semi-skimmed milk (Table 2). During assembly and morning break time (10:30), the children were provided with either $160 \mathrm{ml}$ of semiskimmed milk (Organic Milk, Acorn Dairy, UK) served in a small milk carton or $153 \mathrm{~g}$ of apple (Sweet Gala Apples, Tesco, UK) cut up into segments, which they had $15 \mathrm{~min}$ to consume (before lessons). To ensure the freeliving nature of this study, the quantity of apple provided to the children was identified as a typical portion of apple using the Microdiet Software Package (Microdiet V2.8.5, Downlee Systems Ltd., UK). Therefore, to ensure the snacks were isoenergetic and energy density matched, the quantity of semi-skimmed milk provided was established at $160 \mathrm{ml}$, a similar amount to that advised by the Food Standards Agency and School Foods Trust (189 $\mathrm{ml}$ ). It was not the intention of the study to manipulate the physical composition of the snacks, given the rationale and free-living nature of the study. The nutritional compositions of the snacks are provided in Table 2.

\subsection{Measures}

The children were asked to complete VAS exploring hunger, prospective food consumption and fullness at various time points throughout the two $1-\mathrm{d}$ test sessions
Table 2. Composition of the mid-morning snacks.

\begin{tabular}{|c|c|c|}
\hline & Semi-skimmed milk ${ }^{1}$ & Apple $^{2}$ \\
\hline \multicolumn{3}{|l|}{ Portion } \\
\hline Product (g/ml) & 160 & 153 \\
\hline \multicolumn{3}{|l|}{ Energy } \\
\hline Per portion (MJ) & 0.3 & 0.3 \\
\hline Density (kJ/g) & 2.0 & 2.1 \\
\hline \multicolumn{3}{|l|}{ Protein } \\
\hline Per portion $(\mathrm{g})$ & 5.4 & 0.6 \\
\hline Percentage of energy (\%) & 33.5 & 3.2 \\
\hline \multicolumn{3}{|l|}{ Fat } \\
\hline Per portion $(\mathrm{g})$ & 2.7 & 0.2 \\
\hline Percentage of energy (\%) & 16.8 & 1.0 \\
\hline \multicolumn{3}{|l|}{ Carbohydrate } \\
\hline Per portion $(\mathrm{g})$ & 8.0 & 18.1 \\
\hline Percentage of energy (\%) & 50 & 96 \\
\hline \multicolumn{3}{|l|}{ Fibre } \\
\hline Per portion $(\mathrm{g})$ & 0 & 2.8 \\
\hline Glycaemic index & 30 (Low) & 38 (Low) \\
\hline
\end{tabular}

${ }^{1}$ Organic milk, Acorn dairy, UK; ${ }^{2}$ Sweet gala apples, Tesco, UK.

[immediately before and after breakfast, immediately before and after the milk or fruit snack, 11:30, 12:00, 13:00, 14:00, 15:00, 16:00, 17:00, 18:00, 19:00, 20:00, 21:00]. Appetite responses were rated on $100 \mathrm{~mm}$ horizontal lines, to each of these questions, "How hungry do you feel now?" anchored by very hungry (100) and not at all hungry (0); "How full do you feel now?" anchored by very full (100) and not full at all (0); prospective food consumption and "How much would you like to eat now?" anchored by a lot (100) and nothing at all (0).

The children consumed their lunch (12:00-13:00) 90 min following the mid-morning snacks. The lunch took the form of a school dinner or packed lunch, depending on each child's habitual preference. Fifteen children (girls $\mathrm{n}=10$; boys $\mathrm{n}=5$ ) chose school dinner, whilst 10 children (girls $n=4$; boys $n=6$ ) opted for packed lunch.

All school dinners were cooked on site and followed the 3-wk rota imposed by the local city council. The food and drink items and portion sizes provided during each test session for each school year group were the same. During the first test session the children chose their preferred school dinner, which they then were reminded to choose during the second test session. Following school dinner intake, each food and drink item left over by the children were covertly weighed to the nearest gram by the research team.

If the child had a packed lunch, the parents/guardians 
were asked to weigh and record in a food diary, the food and drinks items and portion sizes provided for the first test session, and any leftover food and drink items that their child returned home. In order for parents/guardians to replicate their child's packed lunch intake for the second test session, they were provided with a photocopy of the food and drink items along with portion sizes that their child had consumed in their packed lunch during the first test session.

Following lunch, the children continued with their normal school activities and lessons. After the children finished school (15:15), their parents/guardians were asked to weigh and record in a food diary, their child's food and drink intake for the rest of the evening until bedtime.

Breakfast, lunch (school dinner and packed lunch) and evening energy intake and macronutrient composition (percentage contribution of carbohydrate, protein and fat to lunch and evening energy intake) were determined using the Microdiet Software Package (Microdiet V2.8.5, Downlee Systems Ltd., UK). Breakfast, lunch (school dinner and packed lunch) and evening energy intake (MJ) were then totalled for each child in addition to percentage contribution of carbohydrate, protein and fat.

\subsection{Statistical Analysis}

The statistical package SPSS-PC (SPSS Inc., Chicago, IL) was used for all data analysis. Between group (gender) participant characteristics were analysed using independent t-tests (Table 1). Visual analogue scale ratings for subjective appetite (hunger, prospective food consumption and fullness) were calculated as time-averaged area under the curve (AUC) for: breakfast, school period (before snack-15:00;4.5 h), evening period (15:00$21: 00 ; 6 \mathrm{~h}$ ) and school and evening period combined (before snack-21:00;10.5 h). Area under the curve values were subsequently analysed using a 2 (mid-morning snack) $\times 2$ (gender) ANOVA (within-between design). Energy intake (MJ) and macronutrient composition (percentage carbohydrate, fat and protein) of breakfast, lunch and evening intake were analysed using a 2 (mid-morning snack) $\times 2$ (gender) ANOVA (within-between design). Means \pm SE were calculated for all data. Significance was set at $P<0.05$ for all analyses

\section{Results}

All subjective appetite ratings are provided in Figure 1. With regards to the breakfast period, there was no main effect of snack or interaction between snack and gender, for hunger $(P=0.33$ and $P=0.83$ respectively $)$, prospective food consumption $(P=0.51$ and $P=0.37$ respectively) or fullness ( $P=0.38$ and $\mathrm{P}=0.58$ respectively).

During the school period (before snack-15:00; $4.5 \mathrm{~h}$ ), there was a main effect of snack for hunger and prospective food consumption (AUC $\times 4.5 \mathrm{~h}$ ), whereby when apple was consumed as a mid-morning snack, as opposed to milk, both girls and boys felt they were less hungry [girls: 43( $\mathrm{sE} 3)$ v. $48(\mathrm{sE} 5) \mathrm{mm}$; boys: $51(\mathrm{sE} 7)$ v. $58\left(\mathrm{SE}^{4}\right)$ $\mathrm{mm}$, respectively, $P=0.02$ ] and could eat less [girls: 43( $\left.\mathrm{SE}^{4}\right)$ v. $49(\mathrm{SE} 5) \mathrm{mm}$; boys: $51\left(\mathrm{sE}^{6} 6\right)$ v. $57\left(\mathrm{sE}^{5}\right) \mathrm{mm}$, respectively, $P=0.02]$. There was no main effect of snack $(P=0.75)$ or interaction between snack and gender $(P=$ 0.36 ) for fullness, with regards to the school period (before snack-15:00; $4.5 \mathrm{~h}$ ).

There were no main effects of snack or interactions between snack and gender during the evening period $(15: 00-21: 00 ; 6 \mathrm{~h})$ and the school and evening period combined (before snack-21:00;10.5 h), for hunger $(P=$ 0.98 and $P=0.34$ respectively), prospective food consumption $(P=0.44$ and $P=0.17$ respectively) or fullness ( $P=0.57$ and $P=0.55$ respectively).

All energy intake and macronutrient composition values for breakfast, lunch (school dinner and packed lunch) and evening intake are provided in Table 3.

There was no main effect of snack or interaction between snack and gender for energy intake (MJ) $(P=0.15$ and $P=0.64$ respectively), percentage carbohydrate $(P=$ 0.09 and $P=0.19$ respectively), protein $(P=0.79$ and $P$ $=0.92$ respectively $)$ and fat $(P=0.22$ and $P=0.26$ respectively) for breakfast intake.

Similarly, there was no main effect of snack or interaction between snack and gender for energy intake (MJ) ( $P=0.74$ and $P=0.68$ respectively), percentage carbohydrate $(P=0.26$ and $P=0.72$ respectively), protein $(P$ $=0.17$ and $P=0.51$ respectively $)$ and fat $(P=0.39$ and $P$ $=0.58$ respectively) for lunch intake.

There was no main effect of snack or interaction between snack and gender for energy intake (MJ) $(P=0.39$ and $P=0.51$ respectively), percentage carbohydrate $(P=$ 0.69 and $P=0.68$ respectively), protein $(P=0.08$ and $P$ $=0.19$ respectively $)$ and fat $(P=0.16$ and $P=0.29$ respectively) for evening intake.

\section{Discussion}

The major finding of this study was that from an appetite control perspective, both fruit and milk should be promoted as mid-morning snacks in primary schools, by local education authorities. To the best of our knowledge, the present study was the first to employ an ecologically valid study design to directly explore the influence on appetite of two dietary intervention schemes (school milk and "The School Fruit and Vegetable Scheme"), currently available to primary schools in the UK.

The present study identified that $7-10 \mathrm{y}$ boys and girls felt less hungry and felt they could eat less over the school day (before snack-15:00; $4.5 \mathrm{~h}$ ) when apple was 


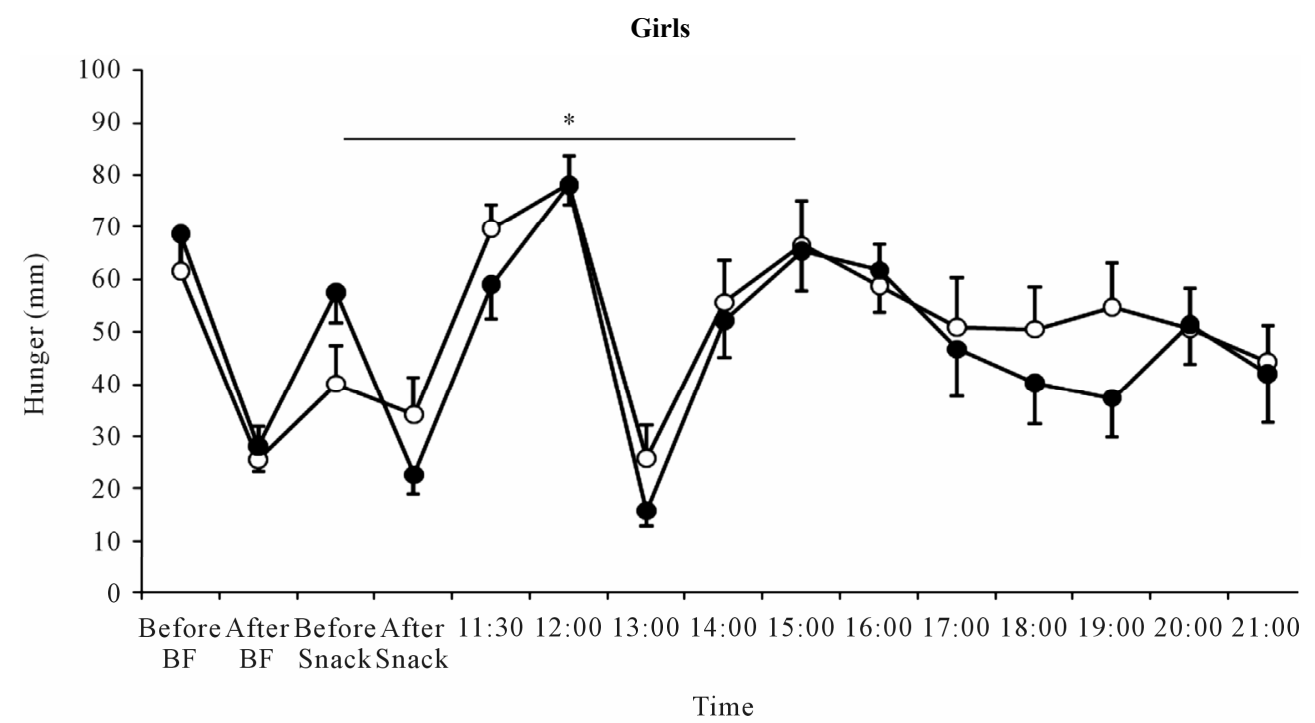

(a)

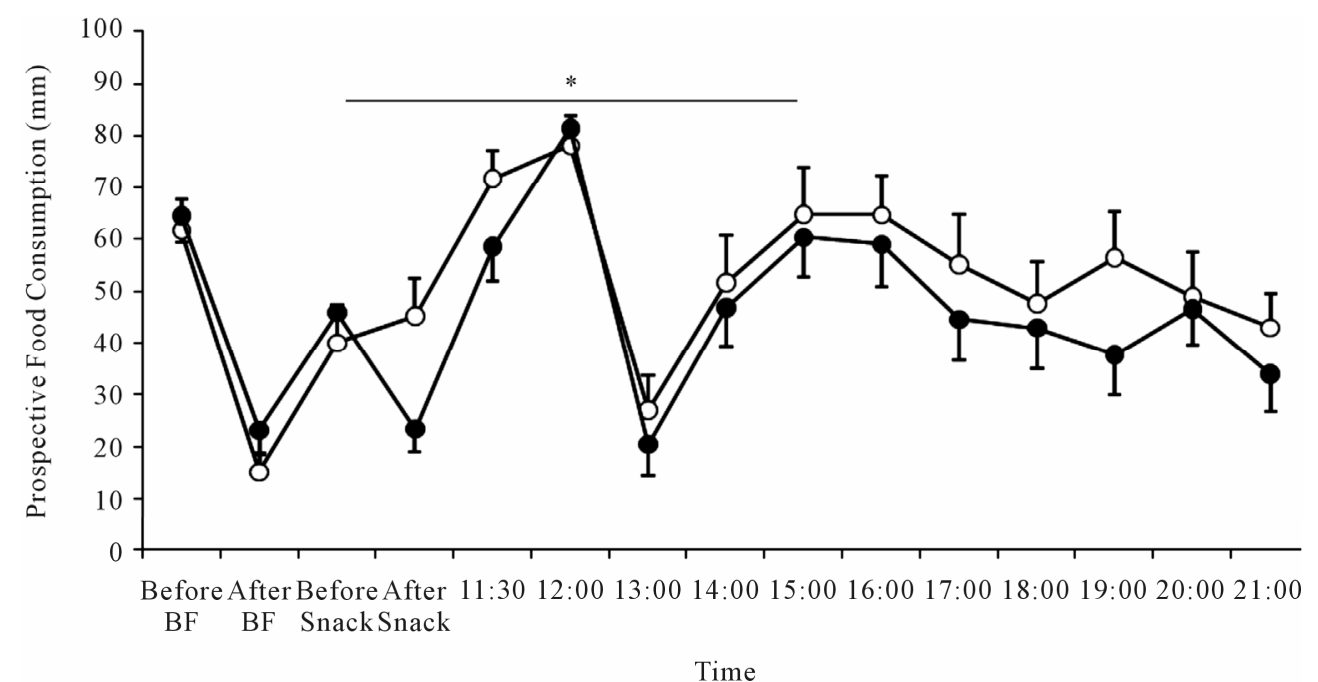

(b)

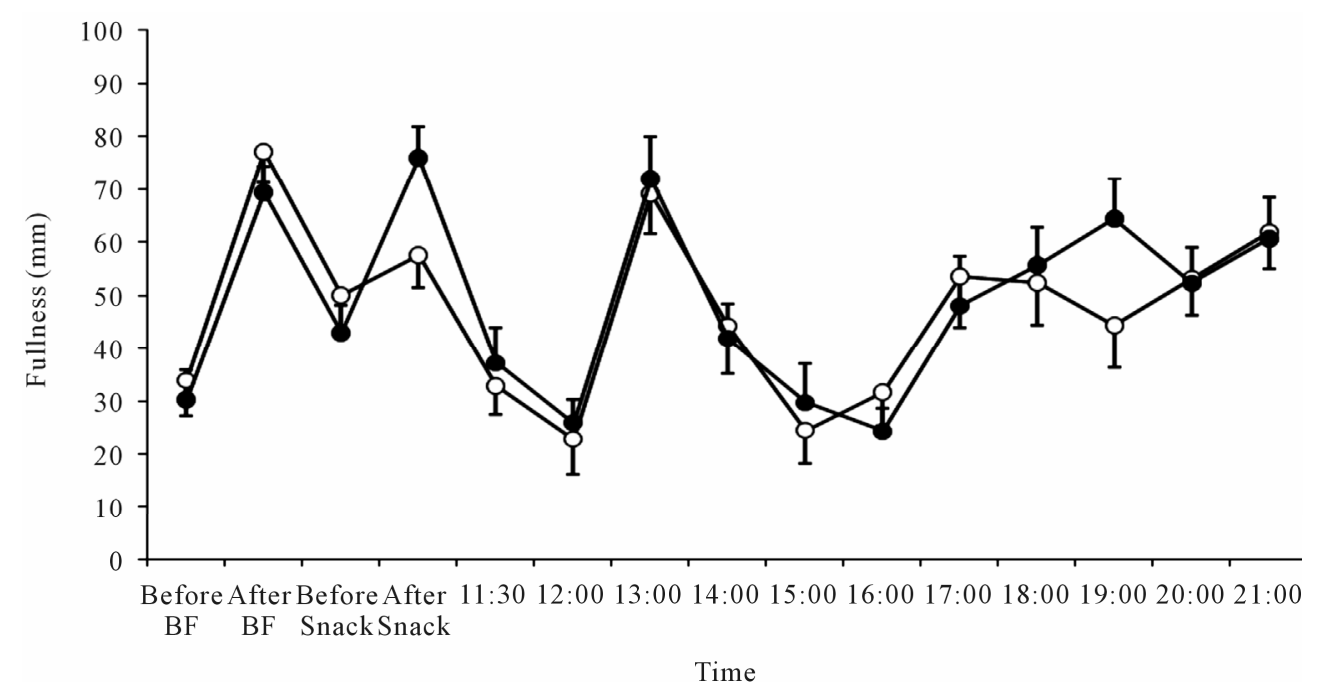

(c) 


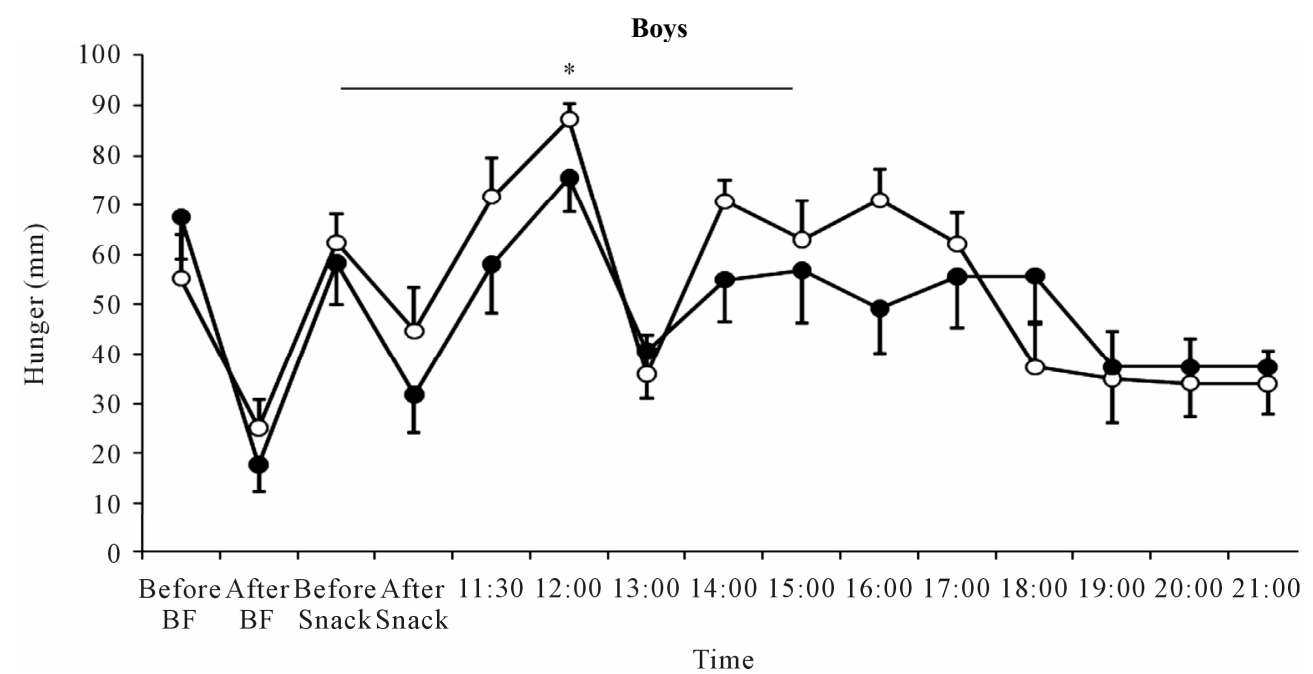

(a)

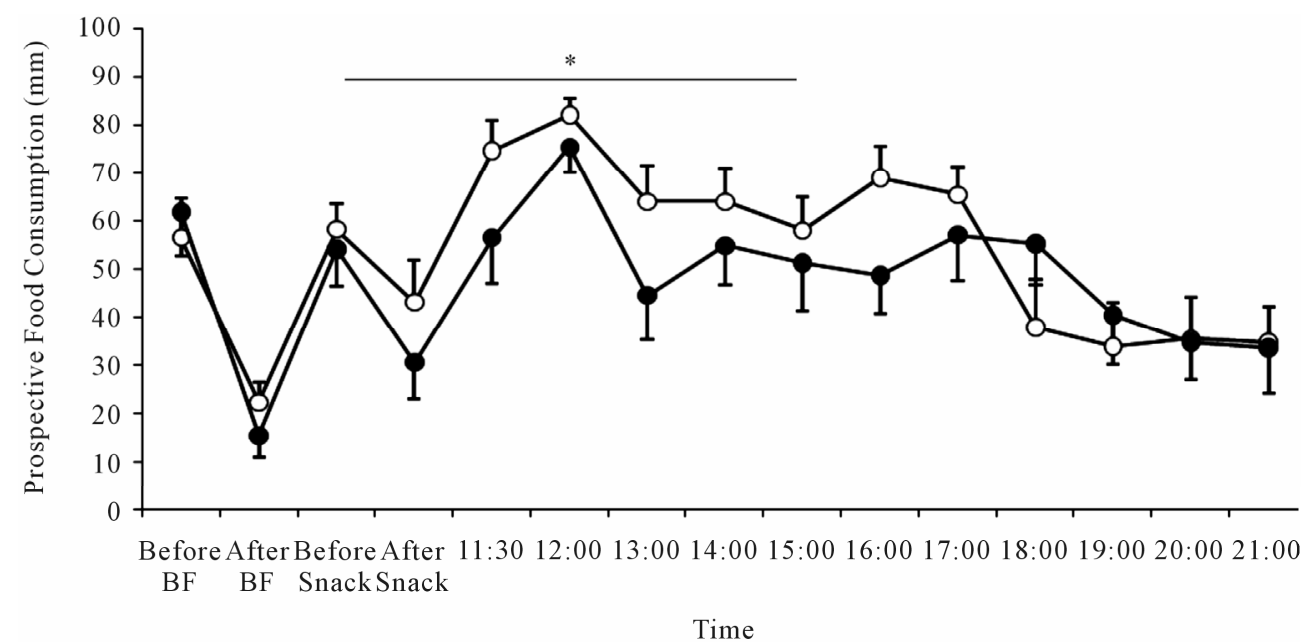

(b)

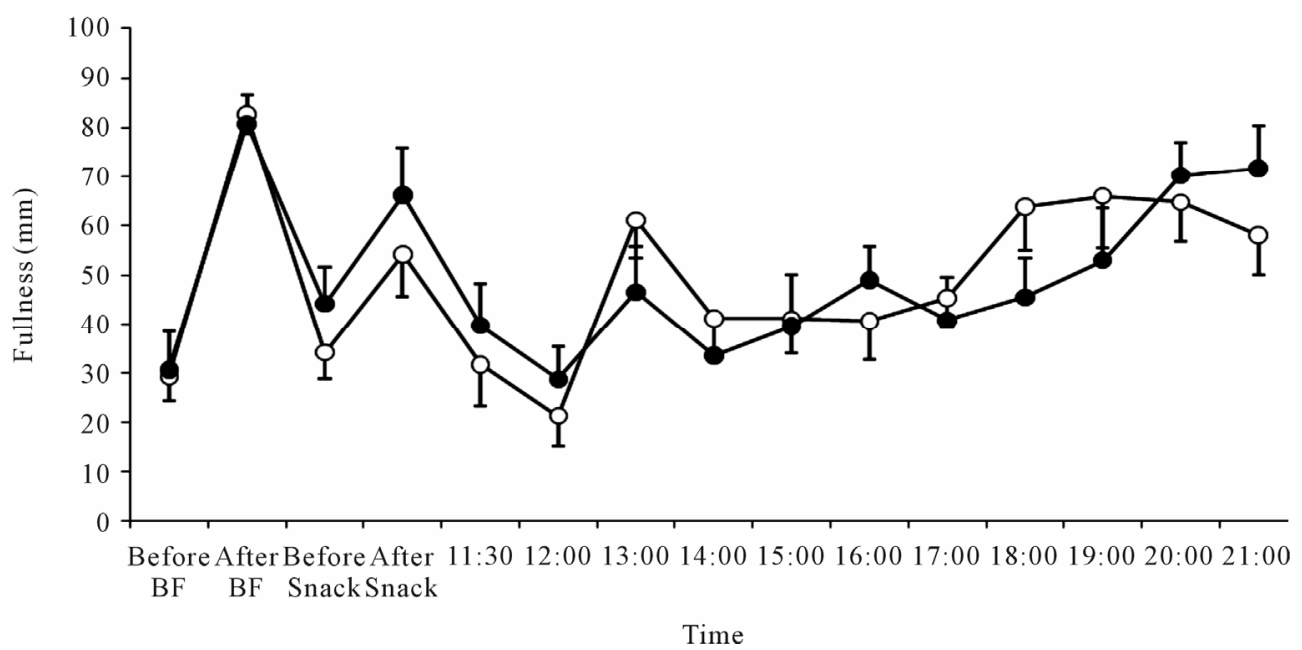

(c)

Figure 1. Subjective appetite [Mean $\pm_{\mathrm{SE}}$ (a) hunger; (b) prospective food consumption; and (c) fullness ratings on the visual analogue scales for the fruit $(\bullet)$ and milk $(\circ)$ test days in girls $(n=14)$ and boys $(n=11)$. BF, breakfast. *Area under the curve values for hunger and prospective food consumption, during the school period (AUC $\times 4.5 \mathrm{~h})$, were significantly lower in the fruit compared to the milk trial, irrespective of gender $(P=0.02$ and $P=0.02$, respectively $)]$. 
Table 3. Energy intake and macronutrient composition (mean values with standard errors) of breakfast, lunch (school dinner and packed lunch) and evening intake, for girls $(n=11)$, boys $(n=14)$ and girls and boys combined $(n=25)$.

\begin{tabular}{|c|c|c|c|c|c|c|c|c|c|c|c|c|c|c|c|c|c|}
\hline & & \multicolumn{8}{|c|}{ Semi-Skimmed Milk } & \multicolumn{8}{|c|}{ Apple } \\
\hline & & \multicolumn{2}{|c|}{$\begin{array}{l}\text { Energy Intake } \\
\text { (MJ) }\end{array}$} & \multicolumn{2}{|c|}{$\begin{array}{c}\text { Carbohydrate } \\
(\%)\end{array}$} & \multicolumn{2}{|c|}{ Protein $(\%)$} & \multicolumn{2}{|c|}{ Fat (\%) } & \multicolumn{2}{|c|}{$\begin{array}{l}\text { Energy Intake } \\
\text { (MJ) }\end{array}$} & \multicolumn{2}{|c|}{$\begin{array}{c}\text { Carbohydrate } \\
(\%)\end{array}$} & \multicolumn{2}{|c|}{ Protein (\%) } & \multicolumn{2}{|c|}{ Fat $(\%)$} \\
\hline & & Mean & $\mathrm{SE}$ & Mean & $\mathrm{SE}$ & Mean & $\mathrm{SE}$ & Mean & $\mathrm{SE}$ & Mean & $\mathrm{SE}$ & Mean & $\mathrm{SE}$ & Mean & $\mathrm{SE}$ & Mean & SE \\
\hline \multirow{3}{*}{ Breakfast } & Girls & 1.37 & 0.15 & 52 & 6 & 13 & 2 & 36 & 6 & 1.22 & 0.13 & 56 & 6 & 13 & 2 & 32 & 6 \\
\hline & Boys & 1.47 & 0.11 & 65 & 6 & 11 & 1 & 23 & 5 & 1.39 & 0.14 & 66 & 6 & 11 & 1 & 23 & 5 \\
\hline & All & 1.41 & 0.09 & 58 & 4 & 12 & 1 & 30 & 4 & 1.29 & 0.10 & 60 & 4 & 12 & 1 & 28 & 4 \\
\hline \multirow{3}{*}{ Lunch } & Girls & 1.83 & 0.18 & 53 & 2 & 13 & 1 & 34 & 2 & 1.89 & 0.23 & 52 & 3 & 14 & 2 & 37 & 3 \\
\hline & Boys & 1.96 & 0.20 & 51 & 3 & 15 & 1 & 34 & 3 & 1.95 & 0.21 & 48 & 2 & 15 & 2 & 35 & 3 \\
\hline & All & 1.88 & 0.13 & 52 & 2 & 14 & 1 & 34 & 2 & 1.92 & 0.16 & 50 & 2 & 14 & 1 & 35 & 2 \\
\hline \multirow{3}{*}{ Evening } & Girls & 3.38 & 0.25 & 22 & 6 & 43 & 5 & 35 & 2 & 3.87 & 0.40 & 22 & 5 & 42 & 4 & 36 & 3 \\
\hline & Boys & 4.48 & 0.55 & 18 & 3 & 46 & 2 & 36 & 3 & 4.55 & 0.53 & 20 & 3 & 39 & 3 & 41 & 4 \\
\hline & All & 3.86 & 0.29 & 20 & 3 & 44 & 3 & 36 & 2 & 4.17 & 0.32 & 21 & 3 & 41 & 3 & 38 & 2 \\
\hline
\end{tabular}

consumed as a mid-morning snack as opposed to milk. However, these fluctuations in subjective hunger and prospective food consumption were transient, whereby during the evening period $(15: 00-21: 00 ; 6 \mathrm{~h})$ and the school and evening period combined (before snack$21: 00 ; 10.5 \mathrm{~h})$ the differences in these subjective sensations did not persist. Indeed, it has been suggested that a $10 \%$ difference in $4.5 \mathrm{~h}$ mean or AUC appetite ratings when comparing the satiating properties of two foods is seen as a "reasonable and realistic difference" [27]. In the present study, for both boys and girls the difference in AUC values for hunger and prospective food consumption ratings, between the snacks did not equate to $10 \%$, suggesting a lack of practical significance.

It has been postulated that when comparing the satiating effects of two different foods, factors such as palatability, energy density, physical composition, motivational appetite state, environmental cues and cognition should be considered [20]. In addition, weight [28], energy content [29], expectations of fullness [30], fibre content [31], macronutrient composition [32], volume of food [33] and mastication [34,35] have also been suggested to influence satiety. Indeed, in the present study the snacks were similar in weight, and matched for energy content, energy density and glycaemic index. However, there were a number of differences with regards to the physical properties of the snacks (carbohydrate and fibre content, food form/texture and volume) which may explain the greater satiating effect of fruit compared to milk in the present study.

Despite the possible explanations such reductions in subjective hunger and prospective food consumption following the consumption of apple did not translate into a decrease in absolute energy consumed at lunch or during the evening period. Consequently, this finding provides further support for a lack of practical significance. Specifically, with regards to the influence of apple consumption on appetite, these findings disagree with those available in the adult literature, whereby lunch intake was reduced by $15 \%$ when solid apple versus liquid apple (applesauce; apple juice) were consumed prior to a test meal [30]. However, the time delay between the preload and test meal in the present study and latter [30] was substantially different, $90 \mathrm{~min}$ and $15 \mathrm{~min}$ respectively. Thus the influence of food form (solid v. liquid) on energy intake compensation is thought to be less important, with the time interval between food preloads and subsequent meals taking precedent [36,37].

Interestingly, the importance of timing of test meals has been the focus of paediatric food preload studies [10, 38]. The former study identified that following the ingestion of $45 \mathrm{~g}$ of sucrose in water, food intake was suppressed at a meal $30 \mathrm{~min}$ later but not at 90 min later in 9 $10 \mathrm{y}$ children. Thus it seems that a child's response to previous dietary manipulation is interfered with when a test meal is provided $90 \mathrm{~min}$ after a food preload [1]. Therefore, manipulating the time between the midmorning snack and lunch intake may have influenced the energy intake results in the present study. The intention of the present study however, was to explore the effectiveness of current school arrangements with regards to the provision of mid-morning snacks and their effects on appetite control in primary school aged children.

Given the intention of conducting an ecologically valid study, we believe various aspects of the study methodology to have been robust (provision of representative mid- 
morning snacks which were isoenergetic; matched for energy density; rigorous assessment of subjective appetite and energy intake; use of a free-living primary school environment). A potential limitation of the present study was that no hormonal indicators of appetite were sought. Therefore, there is a requirement for both subjective appetite and short term hormonal regulators of appetite to be assessed concurrently in future paediatric appetite control studies.

In conclusion, the present study identified that from an appetite control perspective both fruit and milk should be promoted as mid-morning snacks in primary schools, based on children's (7 - 11 y) preferences. Given the current and prospective levels of childhood obesity in the UK [5], future studies which include the measurement of appetite hormones will help to provide an understanding of factors influencing young people's food intake. The development of such an evidence base can then be disseminated to local education authorities as a means of education with regards to young people's dietary habits during school hours.

\section{Acknowledgements}

All authors have seen and approved the content of the manuscript. P. L. S. R developed the initial idea and wrote the manuscript. E. J. S and C. J. D.-R. provided academic advice and consultation, and helped write the manuscript. This work was supported by The Dairy Council and Acorn Dairy, however the study sponsors did not have a role in study design, data collection, analysis, interpretation or the writing of this report. The authors would also like to thank the schools, teachers, parents and students who participated.

\section{REFERENCES}

[1] C. J. Dodd, "Energy Regulation in Young People," Journal of Sports Science and Medicine, Vol. 6, 2007, pp. 327-336.

[2] A. R. Hughes, A. Sherriff, D. A. Lawlor, A. R. Ness and J. J. Reilly, "Incidence of Obesity during Childhood and Adolescence in a Large Contemporary Cohort," Preventive Medicine, Vol. 25, 2011, pp. 300-304.

[3] S. L. Gortmaker, L. W. Y. Cheung, K. E. Peterson, G. Chomitz, J. H. Cradle, H. Dart, M. K. Fox, R. B. Bullock, A. M. Sobol, G. Colditz, A. E. Field and N. Laird, "Impact of a School-Based Interdisciplinary Intervention on Diet and Physical Activity among Urban Primary School Children Eat Well and Keep Moving," Archives of Pediatrics \& Adolescent Medicine, Vol. 153, No. 9, 1999, pp. 975-983. doi:10.1001/archpedi.153.9.975

[4] Department of Health, "School Fruit and Vegetable Scheme: Information for Parents," 2004.

[5] R. Craig, J. Mindell and V. Hirani, "Health Survey for England 2008. Physical Activity and Fitness: Summary of
Key Findings," The Health and Social Care Infromation Centre, 2009, pp. 1-21.

[6] S. Abreu, R. Santos, C. Moreira, P. C. Santos, S. Vale, L. Soares-Miranda, J. Mota and P. Moreira, "Milk Intake Is Inversely Related to Body Mass Index and Body Fat in Girls," European Journal of Pediatrics, Vol. 171, 2012, pp. 1467-1474.

[7] L. L. Birch, L. S. McPhee, J. L. Bryant and S. L. Johnson, "Children's Lunch Intake: Effects of Mid-Morning Snacks Varying in Energy Density and Fat Content," Appetite, Vol. 20, No. 2, 1993, pp. 83-94. doi:10.1006/appe.1993.1011

[8] L. L. Birch and M. Deysher, "Conditioned and Unconditioned Caloric Compensation: Evidence for Self-Regulation of Food Intake in Young Children," Learning and Motivation, Vol. 16, 1985, pp. 341-355.

[9] L. L. Birch and M. Deysher, "Caloric Compensation and Sensory Specific Satiety: Evidence for Self Regulation of Food Intake by Young Children," Appetite, Vol. 7, No. 1986, pp. 323-331.

[10] L. L. Birch, L. S. McPhee and S. Sullivan, "Children's Food Intake Following Drinks Sweetened with Sucrose or Aspartame: Time Course Effects," Physiology and Behavior, Vol. 45, 1989, pp. 387-395.

[11] J. E. Cecil, C. N. Palmer, W. Wrieden, I. Murrie, C. Bolton-Smith, P. Watt, D. J. Wallis and M. M. Hetherington, "Energy Intakes of Children after Preloads: Adjustment, Not Compensation," American Journal of Clinical Nutrition, Vol. 82, No. 2, 2005, pp. 302-308.

[12] S. L. Johnson and L. A. Taylor-Holloway, "Non-Hispanic White and Hispanic Elementary School Children's SelfRegulation of Energy Intake," American Journal of Clinical Nutrition, Vol. 83, No. 6, 2006, pp. 1276-1282.

[13] E. H. Zandstra, M. F. Mathey, C. D. Graaf and W. A. V. Staveren, "Short-Term Regulation of Food Intake in Children, Young Adults and the Elderly," European Journal of Clinical Nutrition, Vol. 54, No. 3, 2000, pp. 239-246. doi:10.1038/sj.ejen.1600927

[14] N. Bellissimo, S. G. Thomas, P. B. Pencharz, R. C. Goode and G. H. Anderson, "Reproducibility of Short-Term Food Intake and Subjective Appetite Scores after a Glucose Preload, Ventilation Threshold, and Body Composition in Boys," Applied Physiology, Nutrition, and Metabolism, Vol. 33, No. 2, 2008, pp. 326-337. doi:10.1139/H07-194

[15] H. J. Leidy and E. M. Racki, "The Addition of a ProteinRich Breakfast and Its Effects on Acute Appetite Control and Food Intake in 'Breakfast-Skipping' Adolescents," International Journal of Obesity, Vol. 34, No. 7, 2010, pp. 1125-1133. doi:10.1038/ijo.2010.3

[16] J. F. Wilson, "Preschool Children Maintain Intake of Other Foods at a Meal including Sugared Chocolate Milk," Appetite, Vol. 16, No. 1, 1991, pp. 61-67. doi:10.1016/0195-6663(91)90112-6

[17] J. F. Wilson, "Preschoolers Mid-Afternoon Snack Intake Is Not Affected by Lunchtime Food Consumption," Appetite, Vol. 33, No. 3, 1999, pp. 319-327. doi:10.1006/appe.1999.0266 
[18] J. F. Wilson, "Does Type of Milk Beverage Affect Lunchtime Eating Patterns and Food Choice by Preschool Children?" Appetite, Vol. 23, 1994, pp. 90-92.

[19] A. Hägg, T. Jacobson, G. Nordlund and S. Rossner, "Effects of Milk or Water on Lunch Intake in Preschool Children," Appetite, Vol. 31, No. 1, 1998, pp. 83-92. doi:10.1006/appe.1997.0152

[20] J. Blundell, C. De Graaf, T. Hulshof, S. Jebb, B. Livingstone, A. Lluch, D. Mela, S. Salah, E. Schuring, H. Van Der Knaap and M. Westerterp, "Appetite Control: Methodological Aspects of the Evaluation of Foods," Obesity Reviews, Vol. 11, No. 3, 2010, pp. 251-270. doi:10.1111/j.1467-789X.2010.00714.X

[21] T. J. Cole, M. C. Bellizzi, K. M. Flegal and W. H. Dietz, "Establishing a Standard Definition for Child Overweight and Obesity Worldwide: International Survey," British Journal of Nutrition, Vol. 320, 2000, pp. 1240-1246.

[22] R. L. Mirwald, A. D. Baxter-Jones, D. A. Bailey and G. P. Beunen, "An Assessment of Maturity from Anthropometric Measurements," Medicine \& Science in Sports \& Exercise, Vol. 34, No. 4, 2002, pp. 689-694. doi:10.1097/00005768-200204000-00020

[23] T. van Strien and P. Oosterveld, "The Children's DEBQ for Assessment of Restrained, Emotional, and External Eating in 7- to 12-Year-Old Children," International Journal of Eating Disorders, Vol. 41, No. 1, 2008, pp. 72-81. doi:10.1002/eat.20424

[24] N. Hanet, S. Salah and A. Lluch, "A training Session to Rate Appetite Feelings Increases the Robustness of Methodology," Appetite, Vol. 55, No. 1, 2010, p. 168. doi:10.1016/j.appet.2010.05.064

[25] A. M. Stephen, B. Teucher, B. J. Bates, L. J. Bluck, A. P. Mander and H. MacKenzie, "UK National Diet and Nutrition Survey: A Study to Decide the Dietary Assessment Method for the New Rolling Programme," International Conference on Diet and Physical Activity Methods, 2009.

[26] R. J. Stubbs, D. A. Hughes, A. M. Johnstone, S. Whybrow, G. W. Horgan, N. A. King and J. E. Blundell, "Rate and Extent of Compensatory Changes in Energy Intake and Expenditure in Response to Altered Exercise and Diet Composition in Humans," American Journal of Physiology-Regulatory, Intergrative and Comparative Physiology, Vol. 286, 2004, pp. 350-358.

[27] A. Flint, A. Raben, J. E. Blundell and A. Astrup, "Reproducibility, Power and Validity of Visual Analogue
Scales in Assessment of Appetite Sensations in Single Test Meal Studies," International Journal of Obesity, Vol. 24, 2000, pp. 38-48.

[28] R. P. Bolton, K. W. Heaton and L. F. Burroughs, “The Role of Dietary Fiber in Satiety, Glucose, and Insulin: Studies with Fruit and Fruit Juice," American Journal of Clinical Nutrition, Vol. 34, 1981, pp. 211-217.

[29] R. D. Mattes, "Soup and Satiety," Physiology and Behavior, Vol. 83, 2005, pp. 739-747.

[30] J. E. Flood-Obbagy and B. J. Rolls, "The Effect of Fruit in Different Forms on Energy Intake and Satiety at a Meal," Appetite, Vol. 52, No. 2, 2009, pp. 416-422. doi:10.1016/j.appet.2008.12.001

[31] N. C. Howarth, E. Saltzman and S. B. Roberts, "Dietary Fibre and Weight Regulation," Nutrition Reviews, Vol. 59, 2001, pp. 129-139.

[32] J. E. Blundell, C. L. Lawton, J. R. Cotton and J. I. Macdiarmid, "Control of Human Appetite: Implications for the Intake of Dietary Fat," Annual Review of Nutrition, Vol. 16, 1996, pp. 285-319.

[33] N. Read, S. French and K. Cunningham, "The Role of the Gut in Regulating Food Intake in Man," Nutrition Reviews, Vol. 52, No. 1, 1994, pp. 1-10. doi:10.1111/j.1753-4887.1994.tb01347.x

[34] J. G. C. Brand, R. H. Agan and M. Hain, "Chemical Senses in the Release of Gastric and Pancreatic Secretions," Annual Review of Nutrition, Vol. 2, 1982, pp. 249-276.

[35] R. D. Mattes, "Dietary Compensation by Humans for Supplemental Energy Provided as Ethanol or Carbohydrate in Fluids," Physiology and Behavior, Vol. 59, No., 1996, pp. 179-187.

[36] E. Almiron-Roig, Y. Chen and A. Drewnowksi, "Liquid Calories and the Failure of Satiety: How Good Is the Evidence?" Obesity Reviews, Vol. 4, 2003, pp. 201-212.

[37] E. Almiron-Roig, S. Y. Flores and A. Drewnowski, "No Difference in Satiety or in Subsequent Energy Intakes between a Beverage and a Solid Food," Physiology and Behavior, Vol. 82, No. 4, 2004, pp. 671-677. doi:10.1016/j.physbeh.2004.06.003

[38] G. H. Anderson, S. Saravis, R. Schacher, S. Zlotkin and L. A. Leiter, "Aspartame: Effect on Lunch-Time Food Intake, Appetite and Hedonic Response in Children," Appetite, Vol. 13, No. 2, 1989, pp. 93-103. doi:10.1016/0195-6663(89)90107-4 